\title{
RESEARCH
}

Open Access

\section{What drives us apart? Decomposing intersectional inequalities in cigarette smoking by education and sexual orientation among U.S. adults}

\author{
Nada Amroussia ${ }^{1 *}$ (D), Jennifer L. Pearson ${ }^{2,3}$ and Per E. Gustafsson ${ }^{4}$
}

\begin{abstract}
Background: Socio-economic and sexual orientation inequalities in cigarette smoking are well-documented; however, there is a lack of research examining the social processes driving these complex inequalities. Using an intersectional framework, the current study examines key processes contributing to inequalities in smoking between four intersectional groups by education and sexual orientation.

Methods: The sample (28,362 adults) was obtained from Wave 2 (2014-2015) of the Population Assessment of Tobacco and Health (PATH) Study. Four intersectional positions were created by education (high- and loweducation) and sexual orientation (heterosexual or lesbian, gay, bisexual, or queer/questioning (LGBQ). The joint inequality, the referent socio-economic inequality, and the referent sexual orientation inequality in smoking were decomposed by demographic, material, tobacco marketing-related, and psychosocial factors using non-linear Oaxaca decomposition.

Results: Material conditions made the largest contribution to the joint inequality (9.8 percentage points (p.p.), 140.9\%), referent socio-economic inequality (10.01 p.p., 128.4\%), and referent sexual orientation inequality (4.91 p.p., 59.8\%), driven by annual household income. Psychosocial factors made the second largest contributions to the joint inequality (2.12 p.p., 30.3\%), referent socio-economic inequality (2.23 p.p., 28.9\%), and referent sexual orientation inequality (1.68 p.p., 20.5\%). Referent sexual orientation inequality was also explained by marital status (20.3\%) and targeted tobacco marketing (11.3\%).

Conclusion: The study highlights the pervasive role of material conditions in inequalities in cigarette smoking across multiple dimensions of advantage and disadvantage. This points to the importance of addressing material disadvantage to reduce combined socioeconomic and sexual orientation inequalities in cigarette smoking.
\end{abstract}

Keywords: Sexual and Gender minorities, Education, Cigarette smoking, Intersectionality, Health inequality, BlinderOaxaca decomposition

\footnotetext{
* Correspondence: namroussia@nevada.unr.edu

${ }^{1}$ Division of Social and Behavioral Health, University of Nevada, Reno, USA

Full list of author information is available at the end of the article
}

(c) The Author(s). 2019 Open Access This article is distributed under the terms of the Creative Commons Attribution 4.0 International License (http://creativecommons.org/licenses/by/4.0/), which permits unrestricted use, distribution, and reproduction in any medium, provided you give appropriate credit to the original author(s) and the source, provide a link to the Creative Commons license, and indicate if changes were made. The Creative Commons Public Domain Dedication waiver (http://creativecommons.org/publicdomain/zero/1.0/) applies to the data made available in this article, unless otherwise stated. 


\section{Background}

Socio-economic as well as sexual orientation inequalities in cigarette smoking are well-documented among U.S. adults [1-9]. Cigarette smoking prevalence is significantly higher among people with low socio-economic status (SES) [1-5]; in $2018,23.1 \%$ of adults without a high school degree were current smokers, compared to $10.7 \%$ of adults who had an undergraduate degree [5]. Similarly, lesbian, gay, bisexual, and queer/questioning (LGBQ) adults are disproportionately burdened by cigarette smoking, with $20.3 \%$ LGBQ adults reporting current smoking in 2018 compared to only $13.7 \%$ of heterosexual adults $[1,5-8]$. These inequalities in smoking could potentially be reflected in inequalities in smoking-attributed morbidity and mortality disadvantaging low SES and LGBQ adults [9].

Socio-economic inequalities and sexual orientation inequalities in cigarette smoking have conventionally been understood, studied, and addressed as separate axes of inequalities [10-17]. Such a singular and fragmented approach does not capture how these two axes of inequalities interplay to affect adults' smoking status, as challenged by the framework of intersectionality. The intersectional framework is increasingly used in public health research to elucidate the complexity of health inequalities [18-20]. Intersectionality assumes that people's social positions are shaped by interlocking rather than separate axes of power relations stemming from, mutually constructed social factors, including (among others,), sexual orientation, socio-economic status, race, and gender. These interlocking power relations create a complex web of social inequalities determining people's advantage and disadvantage [18-20]. According to the intersectional approach, an individual's experience and his/her health, "are not simply the sum of their parts" [21]; for example, the health and the implications of being an LGBQ adult differ between low-educated LGBQ adults and high-educated LGBQ adults [21].

Intersectionality considers that social inequalities can be reinforced or contested through different social processes of oppression or privilege [21]. In this sense, the intersectional framework allows examining health inequalities not only at the intersection of multiple social positions (e.g. the intersection of sexual orientation and socio-economic status), but also at the intersections of different social processes (e.g. material disadvantage and sexual orientation-based discrimination). This has the potential to yield a deeper, more specific, and realistic understanding of health inequalities [21]. To the authors' knowledge, however, only a few studies have examined intersectional inequalities in smoking [22-24]. These studies have pointed out the important role of the intersections of sexual orientation, with gender, age, gender identity, and to a lesser extent race/ethnicity in explaining the patterns of cigarette smoking among U.S. adults and youth [22-24]. In a recent study (Amroussia N, Gustafsson PE, Pearson JL: Do inequalities add up? Intersectional inequalities in smoking by sexual orientation and education among U.S. adults, unpublished), we found complex patterns of cigarette smoking among U.S. adults at the intersection of sexual orientation and education, thereby, socio-economic and sexual orientation inequalities in cigarette smoking do not add up in expected patterns. This small collection of studies illustrate the unique and policy-relevant knowledge gained from considering axes of inequality as complex rather than disentangled phenomena.

A key challenge is understanding the underlying social processes that may generate, amplify or temper inequalities between complex social positions [21], as this evidence would enable generating evidence necessary to develop tailored and effective smoking prevention programs and policies. However, attempts to explain the combination of socio-economic and sexual orientation inequalities in cigarette smoking are rare $[15,17]$. Drawing on the literature on socioeconomic inequalities and sexual orientation inequalities in smoking, access to material and social resources (e.g. high income and access to social support) might counteract socio-economic and sexual orientation inequalities in cigarette smoking [10, $11,13,14,17,25]$, but other oppressive processes (e.g. financial stress, lack of health insurance, and tobacco marketing strategies targeting disadvantaged subpopulations), might exacerbate these inequalities [10, 26-30]. However, how these social processes may play out in the context of interacting and complex inequalities across socio-economic status and sexual orientation have not been studied previously.

Building on our recent study that examined inequalities in cigarette smoking at the intersection of sexual orientation and education (Amroussia N, Gustafsson PE, Pearson JL: Do inequalities add up? Intersectional inequalities in smoking by sexual orientation and education among U.S. adults, unpublished), the aim of the current study is to examine key processes contributing to these inequalities, using non-linear Blinder-Oaxaca decomposition method. Blinder-Oaxaca decomposition analysis method has gained attention in recent years in health inequalities' research, including research on intersectional inequalities [31], as it allows not only quantifying inequalities in health between two distinct groups, but also attributing this inequality to the unequal distribution of individual factors [32].

\section{Methods}

\section{Study population}

The sample was drawn from the Wave 2 Population Assessment of Tobacco and Health (PATH) Study, conducted between October 2014 and October 2015. The PATH Study is a nationally representative longitudinal 
cohort study of non-institutionalized US adults and youth aged 12 years and older [33]. The initial sample included 45,971 US adults and youth, and the Wave 2 sample consisted of 28,362 adults ages 18 and over. The weighted retention rate of Wave 2 adult interviews was 83.1\% [34].

A four-stage, stratified probability sample design was employed with oversampling young adults (18-24 years), African Americans, and adult tobacco users. Information on tobacco use behavior, attitudes and beliefs, as well as tobacco-related health outcomes were collected using Audio-Computer Assisted Self-Interviews [33].

\section{Measures}

\section{Outcome: current cigarette smoking}

Current cigarette smoking was operationalized as "yes" if the participants fulfilled both of the following two conditions: 1) reported current cigarette use on "every day" or "some days"; as well as 2) smoked more than 100 cigarettes in their lifetime [34].

\section{Exposure: intersectional positions by sexual orientation and socio-economic status}

Adult sexual orientation was based on the item "Do you consider yourself to be (1) straight, (2) lesbian or gay, (3) bisexual, or (4) something else?" A dichotomous variable (LGBQ adults vs. heterosexual adults) was created by grouping the three categories "lesbian or gay", "bisexual", and "something else" into one category. Education was used as an indicator of SES and was categorized into two categories: "less than high school diploma" vs. "high school diploma or more". The cut-off point of high school diploma was chosen as previous research has shown that adults with less than high school education are disproportionally burdened by cigarette smoking [5]. The terms "low educated" and "high educated" will be used to refer to "less than high school diploma" vs. "high school diploma or more" respectively.

Based on sexual orientation and education, four mutually exclusive intersectional positions were formed: high educated heterosexual adults defined as the doubly advantaged group; low-educated heterosexual adults; high-educated LGBQ adults; and low-educated LGBQ adults, defined as the doubly disadvantaged group.

In our previous paper (Amroussia N, Gustafsson PE, Pearson JL: Do inequalities add up? Intersectional inequalities in smoking by sexual orientation and education among U.S. adults, unpublished) and following Jackson et al. method [35], three intersectional inequalities were defined: the joint inequality was defined as the inequality in current cigarette smoking between the doubly disadvantaged group (low-educated LGBQ adults) and the doubly advantaged group (high-educated heterosexual adults); the referent socio-economic inequality as the inequality in current cigarette smoking between low-educated heterosexual adults and higheducated heterosexual adults; and the referent sexual orientation inequality as the inequality in current cigarette smoking between high-educated LGBQ adults and high-educated heterosexual adults. The results of our previous study indicated that these inequalities were positive and of substantial size, suggesting the importance of examining factors and processes contributing to these inequalities.

\section{Explanatory factors: processes of privilege and oppression}

Following the intersectional framework [21], processes of oppression and privilege that might reinforce or mitigate health inequalities were identified. Three factorgroups were chosen to assess these processes. These groups reflected material conditions, tobacco marketingrelated factors, and psychosocial factors.

Material conditions were measured using five variables: annual household income, employment status, receiving assistance, housing, and health insurance. Participants were asked "which of the following categories best describes your total household income in the past 12 months?", and a derived variable was created by dividing income into five groups: $<\$ 10,000, \$ 10,000-\$ 24,999, \$ 25,000-\$ 49,999, \$ 50$, $000-\$ 99,999$, and $\$ 100,000$ or more, according to the PATH study codebook [36]. Employment status was categorized into "full-time", "part-time", and "unpaid", with full-time employment considered the most advantaged groups as it is more likely to provide benefits, such as health insurance, and also higher income. Receiving assistance was coded as "yes" and "no". Housing was based on the item "do you own or rent your home?" and was categorized into "owned", "rented", and "something else", reasoning that those who owns their dwelling have a financial security compared to those who rent. Health insurance was categorized into "private insurance", "Medicaid/Medicare and other insurance", and "no insurance", with adults having private insurance representing the most advantaged group, as private insurance in the U.S. is both more costly and tend to involve greater coverage and benefits.

Tobacco marketing-related factors were measured using three variables chosen to capture and differentiate the current major forms of tobacco marketing in the U.S.: exposure to contextually-targeted tobacco advertisements in the physical environment, exposure to individuallytargeted tobacco marketing through direct mailings of coupons or promotions, and exposure to tobacco advertisements in media such as newspapers and websites.

Exposure to contextual-level targeting advertisement (yes vs. no) was based on two items: "in past 30 days, noticed cigarettes or other tobacco products being advertised: at events such as fairs, festivals, or sporting events" and "in past 30 days, noticed cigarettes or other 
tobacco products being advertised: on posters or billboards". Exposure to individual-targeted tobacco marketing (yes vs. no) was assessed through the item "In past 12 months, received promotions or coupons in the mail for cigarettes or tobacco products". Exposure to advertisement on media (yes vs. no) was based on four items: "in past 30 days, noticed cigarettes or other tobacco products being advertised: in newspapers or magazines", "in past 30 days, noticed cigarettes or other tobacco products being advertised: on websites or social media sites", "in past 30 days, noticed cigarettes or other tobacco products being advertised: on radio", and "in past 30 days, noticed cigarettes or other tobacco products being advertised: on television".

Psychosocial factors were measured perceived quality of life and perceived satisfaction with social relationships and activities, both of which were categorized in a comparable manner into good, moderate, and poor quality of life and satisfaction, respectively. Participants were asked "in general, would you say your quality of life" with five response options "excellent", "very good", "good", "fair", and "poor". The categories "excellent", "very good", "good" were collapsed into one category to create a large reference group for the three-level variable perceived quality of life: "poor," "fair," and "good", with adults reporting poor perceived quality of life representing the most disadvantaged group. Perceived satisfaction with social relationships and activities was based on the item "in general, how satisfied are you with your social activities and relationships?" with five response options "extremely satisfied", "very satisfied", "moderately satisfied", "a little satisfied", and "not all satisfied". Similar to the quality of life variable, the categories "extremely satisfied", "very satisfied" were collapsed into one category "very satisfied" to generate a large reference group, and the categories "moderately satisfied" and "a little satisfied" were collapsed into one category "moderately satisfied", resulting in the final three-level variable perceived satisfaction with social relationships and activities ("very satisfied," "moderately satisfied," and "not at all", with adults reporting feeling unsatisfied with social relationships are the most disadvantaged group).

\section{Socio-demographic factors}

Previous research suggests that both socio-economic inequalities and sexual orientation inequalities in cigarette smoking may vary by gender $[37,38]$, age [39], and race/ ethnicity [40]. Additionally, marital status has been linked to cigarette smoking [41, 42]. Variables capturing these factors were, therefore, included in the analysis: gender (men vs. women), age (18-24, 25-44, and 45+), race/ethnicity (White non-Hispanic, Hispanic, and NonWhite non-Hispanic), and marital status (married, separated/widow/divorced, and never married).

\section{Statistical analyses}

The analysis consisted of three steps: two preliminary set of analyses and one set of main analysis. The first set consisted of descriptive analyses that comprised the distribution of sociodemographic factors and indicators of material, marketing and psychosocial processes across the four intersectional social positions, to descriptively illustrate any intersectional inequalities in social processes. The second set of analyses consisted of three multiple logistic regressions where current cigarette smoking was regressed on all social process variables as well as one of the intersectional inequality variables in each regression; the joint inequality, the referent socioeconomic inequality, or the sexual orientation inequality variable. A multicollinearity analysis was conducted to estimate the variance inflation factors (VIFs) for all the variables included in the models [43], using the command vif in STATA 15 (StataCorp, 2017). The results indicated that the variables included in the models were not highly collinear, with a max VIF of 1.65, mean VIF of 1.30, and highest VIF displayed by annual household income, marital status, and age (1.65, 1.55 , and 1.54 respectively).

The proportion differences between intersectional groups illustrated in the first set of analyses, and the logit estimates from the second set of analyses are both used in the third set of analyses, which served to explain the joint inequality, the referent socio-economic inequality, and the referent sexual orientation inequality through non-linear Blinder-Oaxaca decomposition analysis [32, 44].

The non-linear Blinder-Oaxaca method is an extension of the original linear Blinder-Oaxaca decomposition [45, 46] and aims to explain the gap in a binary outcome variable (i.e. current cigarette smoking) between two groups (e.g. low-educated LGBQ adults and higheducated heterosexual adults for the joint inequality) using a set of explanatory variables [32, 44, 47]. The gap in the binary outcome variable (i.e. current cigarette smoking) is, then, decomposed into: i) an "explained" part attributable to the differences in the frequency of observed explanatory factors between the comparison groups, and ii) an "unexplained" part attributable to differences in the estimated coefficients $[32,45]$ or to differences in unobserved explanatory factors [44].

Non-linear decomposition analyses were performed separately for the joint inequality, referent socioeconomic inequality, and referent sexual orientation. The set of explanatory factors included in the models consisted of all social processes' indicators: material conditions, tobacco marketing-related factors, psychosocial factors, as well as socio-demographic factors. The absolute contribution and relative contribution of each factor to the inequalities were, then, computed. The relative contribution of each factor was estimated by dividing the absolute contribution of the factor (on the same 
scale as the inequality; prevalence difference) by the total explained component of the inequality.

The oaxaca command on STATA 15 (StataCorp, 2017) [44] including its update for non-linear decomposition [47], was employed to perform the decomposition analysis. The normalize subcommand was used to compute the total contribution of all categories of each categorical variable. All estimates were weighted using the U.S. adult population in 2013, and variances were estimated using the balanced repeated replication method with Fay's adjustment [34]. Complete case analysis was used for all analyses with an analytical sample of 25,941 participants.

\section{Sensitivity analyses}

The proportions of missing data for all variables were less than 3\% except for annual household income (7.5\%). Two sensitivity analyses were conducted to inform the decisions of using complete case analysis including the income variable, despite its relatively high non-response. The first sensitivity analysis was performed by: 1) excluding observations with missing data on annual household income, and 2) excluding the annual household income variable from the set of explanatory factors in the models. When compared to the main analysis using the same observations but including the income variable, the unexplained portion was substantially higher in the sensitivity analysis (joint inequality: 10.1\%, referent socio-economic inequality: $52.3 \%$, and referent sexual orientation inequality: $20 \%$ ) than in the main analysis (joint inequality: $-1.1 \%$, referent socio-economic inequality: $37.9 \%$, and referent sexual orientation inequality: $19.8 \%)$, suggesting that annual household income is an important explanatory factor.

The second sensitivity analysis was performed by: 1) including all observations with and without missing data on annual household income, and 2) excluding the annual household income variables from the set of explanatory factors in the models. When compared to the first sensitivity analysis with the same set of variables but excluding the income variable, the results were similar, indicating that excluding observations with missing data on annual household income do not yield biased estimates.

As a result, the final analyses reported in the results section employed complete case analysis and included income in the set of explanatory factors.

\section{Results}

The four intersectional groups differ across all sociodemographic groups (gender, age, race/ethnicity, and marital status). For instance, $60.68 \%$ of LGBQ adults with low education were women as compared to $58.74 \%$ of LGBQ adults with high education, $51.19 \%$ of heterosexual adults with high education, and only $47.43 \%$ of heterosexual adults with low education. The largest share of heterosexual adults with low education were aged 45 and above $(61.14 \%)$ as compared to only $26.85 \%$ of LGBQ adults with low education. Additionally, nearly two thirds of LGBQ adults with low education selfidentified as Hispanic (64.34\%) as compared to only $11.97 \%$ of heterosexual adults with high education. More than half of heterosexual adults with high education were married (54.12\%) as compared to only $27.99 \%$ of LGBQ adults with high education.

The prevalence of current cigarette smoking was unequally distributed between the four intersectional positions (Table 1). High-educated heterosexual adults had the lowest prevalence of cigarette smoking (17.4\%), while loweducated heterosexual adults had the highest prevalence of current cigarette smoking (29.7\%). High-educated LGBQ adults had higher prevalence of cigarette smoking (27.4\%) as compared to low-educated LGBQ adults (23.4\%).

The subsequent analyses set sought to examine to what degree these inequalities in smoking, specifically the joint and referent socioeconomic and sexual orientation inequalities, were attributable to corresponding inequalities in social processes' indicators.

\section{Intersectional inequalities in indicators of social processes} The first set of preliminary analyses (Table 1) illustrate to what degree intersectional social positions are reflected in unequal social processes that may underpin inequalities in smoking, as indicated by material conditions, exposure to marketing, and psychosocial factors, while taking socio-demographic factors into account.

Overall, results in Table 1 indicate that the doubly disadvantaged group of low-educated LGBQ adults exhibited the worse life conditions as compared to the other three intersectional groups, including the highest proportions of low annual household income (49.2\%), receiving assistance (36.7\%), rented housing (65.3\%), lack of health insurance (42.8\%), and fair and poor perceived quality of life (respectively 24.4 and $2.2 \%$ ). Conversely, the doubly advantaged group of high-educated heterosexual adults were better off as compared to the three intersectional groups in terms of high annual household income $(21.2 \%)$, access to owned housing $(59.4 \%)$, and access to private insurance $(70.7 \%)$.

Interestingly, the singly disadvantaged group of higheducated LGBQ adults had higher proportion of low income $(17.8 \%)$ and lack of health insurance $(19.0 \%)$ as compared to high-educated heterosexual adults (9.4\%; and $10.5 \%$ respectively). High-educated LGBQ adults were also the most exposed group to contextual-level targeting tobacco advertising $(42.2 \%, \mathrm{p}, 0.16)$ and targeted tobacco marketing (15.4\%), while low-educated LGBQ adults were the most exposed group to tobacco media advertising (56.5\%, p, 0.036). 
Table 1 Descriptive statistics of all variables in the total sample and by intersectional positions of sexual orientation and education

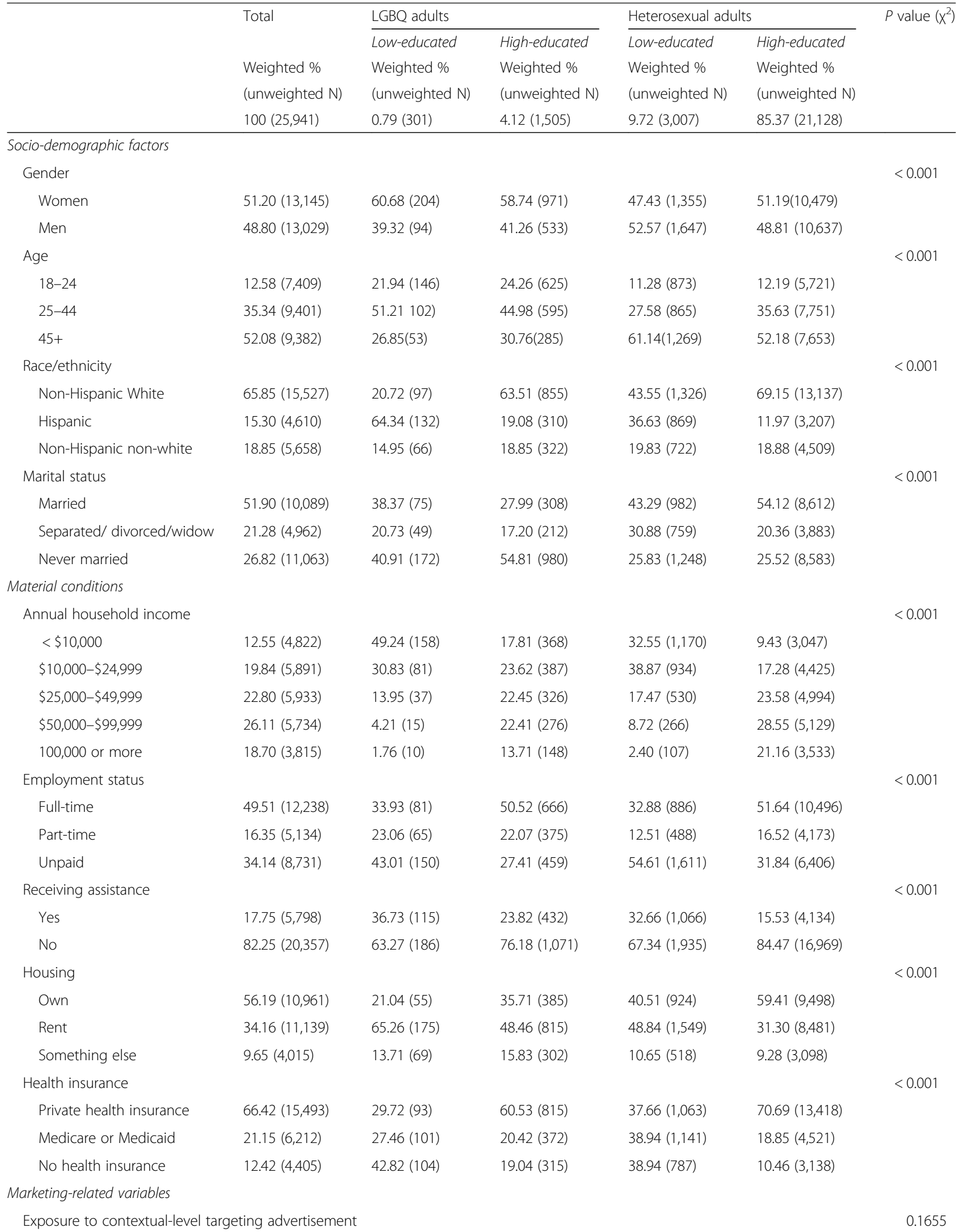


Table 1 Descriptive statistics of all variables in the total sample and by intersectional positions of sexual orientation and education (Continued)

\begin{tabular}{|c|c|c|c|c|c|c|}
\hline \multirow{2}{*}{\multicolumn{2}{|c|}{$\begin{array}{ll}\text { Total } \\
\end{array}$}} & \multicolumn{2}{|l|}{ LGBQ adults } & \multicolumn{2}{|c|}{ Heterosexual adults } & \multirow[t]{5}{*}{$P$ value $\left(x^{2}\right)$} \\
\hline & & Low-educated & High-educated & Low-educated & High-educated & \\
\hline & Weighted \% & Weighted \% & Weighted \% & Weighted \% & Weighted \% & \\
\hline & (unweighted N) & (unweighted N) & (unweighted N) & (unweighted N) & (unweighted N) & \\
\hline & $100(25,941)$ & $0.79(301)$ & $4.12(1,505)$ & $9.72(3,007)$ & $85.37(21,128)$ & \\
\hline Yes & $37.37(10,498)$ & $38.68(137)$ & $42.24(666)$ & $37.54(1,239)$ & $37.25(8,376)$ & \\
\hline No & $62.63(15,651)$ & $61.32(164)$ & $57.76(839)$ & $62.46(1,760)$ & $62.75(12,718)$ & \\
\hline \multicolumn{2}{|c|}{ Exposure to targeted tobacco marketing } & & & & & $<0.001$ \\
\hline Yes & $10.33(3,514)$ & $6.41(29)$ & $14.45(255)$ & $9.07(356)$ & $10.4(2,863)$ & \\
\hline No & $89.67(22,647)$ & $93.59(272)$ & $85.55(1,247)$ & $90.93(2,645)$ & $89.6(18,242)$ & \\
\hline \multicolumn{2}{|c|}{ Exposure to media advertisement } & & & & & 0.0363 \\
\hline Yes & $45.93(12,379)$ & $56.48(174)$ & $50.12(759)$ & $47.03(1,484)$ & $45.59(9,862)$ & \\
\hline No & $54.07(13,764)$ & $43.52(127)$ & $49.88(744)$ & $52.97(1,511)$ & $54.41(11,231)$ & \\
\hline \multicolumn{7}{|l|}{ Intra-personal factors } \\
\hline \multicolumn{2}{|l|}{ Perceived quality of life } & & & & & $<0.001$ \\
\hline Good & $91.16(23,219)$ & $73.36(223)$ & $86.13(1,270)$ & $79.51(2,355)$ & $92.94(19,168)$ & \\
\hline Fair & $7.87(2,584)$ & $24.41(66)$ & $11.68(197)$ & $18.26(576)$ & $6.32(1,705)$ & \\
\hline Poor & $0.97(372)$ & $2.23(9)$ & $2.19(37)$ & $2.23(72)$ & $0.74(244)$ & \\
\hline \multicolumn{2}{|c|}{ Satisfaction with social relations } & & & & & $<0.001$ \\
\hline Very satisfied & $67.56(16,507)$ & $60.17(163)$ & $55.43(792)$ & $61.56(1,720)$ & $68.86(13,678)$ & \\
\hline Moderately satisfied & $30.17(8,877)$ & $35.07(117)$ & $40.15(638)$ & $35.16(1,143)$ & $29.13(6,896)$ & \\
\hline Not at all satisfied & $2.27(778)$ & $4.76(17)$ & $4.418(75)$ & $3.29(137)$ & $2.00(537)$ & \\
\hline \multicolumn{2}{|l|}{ Smoking Status } & & & & & $<0.001$ \\
\hline Non-smokers & $81.01(17,147)$ & $76.55(179)$ & $72.44(900)$ & $70.25(1,582)$ & $82.60(14,310)$ & \\
\hline Smokers & $18.99(9,048)$ & $23.45(122)$ & $27.56(605)$ & $29.75(1,425)$ & $17.40(6,818)$ & \\
\hline
\end{tabular}

Indicators of social processes as predictors of smoking

The second set of preliminary analyses examined to which degree the cited social processes relate to the outcome, current cigarette smoking. Results from three separate multiple logistic regression analyses are reported in Table 2. All three regression analyses were identical expect for the inequality indicator that was included among the set of covariates (joint inequality; referent socio-economic inequality; or referent sexual orientation inequality).

Current cigarette smoking was less common among women, non-Hispanic, or non-Hispanic non-White, but more common among separated, divorced, and unmarried individuals. Smoking was also more common among those of material disadvantage including individuals with low income, receiving assistance, living in rented housing or other arrangements, or having Medicare/Medicaid insurance or no insurance. However, those with part-time or unpaid employment reported less smoking compared to their full-time employed counterparts.

When it comes to the relationship between marketing exposure and smoking, the independent associations were disparate depending on the type of marketing. Adults exposed to individual targeting marketing had nearly 4 times higher odds of cigarette smoking as compared to non-exposed adults (odds ratio (OR) ranged from 3.7 (95\% Confidence Interval (CI): $3.3-4.1$ ) to 3.8 (95\% CI: 3.4-4.2)), but smoking was less common among individuals reporting exposure to media advertisement, and no association was found to contextual-level targeting, taking all other factors into account.

Adults reporting fair to poor quality of life had considerably higher odds of current cigarette smoking as compared to adults reporting good of life (OR ranged from 2.0 (95\% CI: $1.7-2.3$ ) to 3.1 (95\% CI: $2.0-4.8)$ ), as did adults moderately satisfied or not at all satisfied with their social relations (OR ranged from 1.2 (95\% CI: 0.9$1.6)$ to 1.48 (95\% CI: $1.1-1.9)$ ).

Taken together, material, marketing and psychosocial processes as well as sociodemographic factors were all relevant for explaining smoking patterns, of which low income, lack of health insurance (material) targeted tobacco marketing (marketing), poor quality of life (psychosocial), being woman and Hispanic race/ethnicity 
Table 2 Summary of adjusted logistic regression

\begin{tabular}{|c|c|c|c|}
\hline & Joint inequality & Referent socio-economic inequality & Referent sexual orientation inequality \\
\hline & OR $(95 \% \mathrm{Cl})$ & OR $(95 \% \mathrm{Cl})$ & OR $(95 \% \mathrm{Cl})$ \\
\hline \multicolumn{4}{|l|}{ Socio-demographic factors } \\
\hline \multicolumn{4}{|l|}{ Gender } \\
\hline Women & $0.67(0.62,0.72)$ & $0.65(0.60,0.70)$ & $0.68(0.63,0.73)$ \\
\hline Men & 1 & 1 & 1 \\
\hline \multicolumn{4}{|l|}{ Age } \\
\hline $18-24$ & $0.96(0.83,1.12)$ & $0.98(0.85,1.13)$ & $0.98(0.84,1.13)$ \\
\hline $25-44$ & $1.53(1.37,1.71)$ & $1.58(1.42,1.74)$ & $1.54(1.38,1.71)$ \\
\hline $45+$ & 1 & 1 & 1 \\
\hline \multicolumn{4}{|l|}{ Racelethnicity } \\
\hline Non-Hispanic White & 1 & 1 & 1 \\
\hline Hispanic & $0.44(0.37,0.52)$ & $0.38(0.33,0.43)$ & $0.45(0.38,0.53)$ \\
\hline Non-Hispanic non-white & $0.64(0.58,0.71)$ & $0.67(0.60,0.74)$ & $0.64(0.58,0.71)$ \\
\hline \multicolumn{4}{|l|}{ Marital status } \\
\hline Married & 1 & 1 & 1 \\
\hline Separated/ divorced/widow & $1.60(1.41,1.83)$ & $1.55(1.37,1.76)$ & $1.64(1.44,1.87)$ \\
\hline Never married & $1.44(1.27,1.64)$ & $1.41(1.24,1.60)$ & $1.47(1.30,1.66)$ \\
\hline \multicolumn{4}{|l|}{ Material conditions } \\
\hline \multicolumn{4}{|l|}{ Income } \\
\hline Quintile 1 (lowest income) & $2.80(2.33,3.37)$ & $2.69(2.25,3.21)$ & $2.79(2.32,3.36)$ \\
\hline Quintile 2 & $2.52(2.15,2.96)$ & $2.33(2.00,2.72)$ & $2.44(2.09,2.84)$ \\
\hline Quintile 3 & $2.02(1.72,2.37)$ & $2.06(1.76,2.39)$ & $1.95(1.68,2.28)$ \\
\hline Quintile 4 & $1.67(1.44,1.92)$ & $1.65(1.43,1.89)$ & $1.67(1.46,1.91)$ \\
\hline Quintile 5 (highest income) & 1 & 1 & 1 \\
\hline \multicolumn{4}{|l|}{ Employment status } \\
\hline Full-time & 1 & 1 & 1 \\
\hline Part-time & $0.69(0.60,0.78)$ & $0.72(0.63,0.81)$ & $0.68(0.60,0.78)$ \\
\hline Unpaid & $0.75(0.68,0.82)$ & $0.74(0.68,0.82)$ & $0.76(0.69,0.84)$ \\
\hline \multicolumn{4}{|l|}{ Receiving assistance } \\
\hline Yes & $1.23(1.09,1.38)$ & $1.27(1.13,1.42)$ & $1.24(1.10,1.39)$ \\
\hline No & 1 & 1 & 1 \\
\hline \multicolumn{4}{|l|}{ Housing } \\
\hline Own & 1 & 1 & 1 \\
\hline Rent & $1.64(1.48,1.81)$ & $1.65(1.50,1.81)$ & $1.65(1.50,1.81)$ \\
\hline Something else & $1.49(1.29,1.71)$ & $1.48(1.30,1.67)$ & $1.48(1.30,1.67)$ \\
\hline \multicolumn{4}{|l|}{ Health insurance } \\
\hline Private health insurance & 1 & 1 & 1 \\
\hline Medicare or Medicaid & $1.55(1.36,1.76)$ & $1.56(1.37,1.77)$ & $1.56(1.37,1.77)$ \\
\hline No health insurance & $2.12(1.86,2.43)$ & $2.05(1.80,2.34)$ & $2.05(1.80,2.34)$ \\
\hline \multicolumn{4}{|l|}{ Marketing-related variables } \\
\hline \multicolumn{4}{|c|}{ Exposure to contextual-level targeting advertisement } \\
\hline Yes & $0.98(0.88,1.09)$ & $1.02(0.92,1.13)$ & $0.99(0.89,1.09)$ \\
\hline No & 1 & 1 & 1 \\
\hline
\end{tabular}


Table 2 Summary of adjusted logistic regression (Continued)

\begin{tabular}{|c|c|c|c|}
\hline & Joint inequality & Referent socio-economic inequality & Referent sexual orientation inequality \\
\hline & OR $(95 \% \mathrm{Cl})$ & OR $(95 \% \mathrm{Cl})$ & OR $(95 \% \mathrm{Cl})$ \\
\hline Yes & $3.73(3.34,4.17)$ & $3.67(3.29,4.10)$ & $3.79(3.41,4.21)$ \\
\hline No & 1 & 1 & 1 \\
\hline \multicolumn{4}{|c|}{ Exposure to media advertisement } \\
\hline Yes & $0.72(0.65,0.78)$ & $0.72(0.66,0.79)$ & $0.71(0.65,0.78)$ \\
\hline No & 1 & 1 & 1 \\
\hline \multicolumn{4}{|l|}{ Other factors } \\
\hline \multicolumn{4}{|l|}{ Perceived quality of life } \\
\hline Good & 1 & 1 & 1 \\
\hline Fair & $2.10(1.77,2.49)$ & $2.00(1.73,2.33)$ & $2.08(1.76,2.44)$ \\
\hline Poor & $3.11(2.02,4.79)$ & $2.60(1.76,3.84)$ & $3.01(1.99,4.550$ \\
\hline \multicolumn{4}{|c|}{ Satisfaction with social relations } \\
\hline Very satisfied & 1 & 1 & 1 \\
\hline Moderately satisfied & $1.42(1.28,1.57)$ & $1.43(1.30,1.58)$ & $1.39(1.26,1.53)$ \\
\hline Not at all satisfied & $1.19(0.88,1.62)$ & $1.48(1.13,1.94)$ & $1.20(0.90,1.61)$ \\
\hline Inequality & $1.01(0.71,1.44)^{\mathrm{a}}$ & $0.65(0.57,0.74)^{b}$ & $0.82(0.69,0.96)^{c}$ \\
\hline
\end{tabular}

Reference groups for inequality indicators: ${ }^{\mathrm{a}}$ low-educated LGBQ adults, ${ }^{\mathrm{b}}:$ low-educated heterosexual adults, and ${ }^{\mathrm{c}}:$ high-educated LGBQ adults

(socio-demographic) were the individual indicators that showed the strongest independent association to smoking.

Adjusting for all covariates, indicators of referent socio-economic inequality and referent sexual orientation inequality were significant, whereas, the joint inequality's indicator was not significant. These inequalities are (were) analyzed in greater detail in the subsequent decomposition analyses.

\section{The contribution of social processes to joint, referent} socio-economic and referent sexual orientation inequality The final set of analyses sought to estimate to which degree the social processes' unequal distribution across intersectional social positions on the one hand, and their independent association with smoking on the other, contributed to the intersectional inequalities in smoking. A summary of decomposition analyses is displayed in Table 3, and Fig. 1 shows the absolute contributions of explanatory variables to the inequalities. The models explained sizeable proportions of the inequalities in current cigarette smoking: $101.4 \%$ of the joint inequality, $60.1 \%$ of the referent socio-economic inequality, and $80.2 \%$ of the referent sexual orientation inequality.

Material conditions made the largest contribution to all the inequalities; the joint inequality (9.8 percentage point (p.p.), 140.9\%), referent socio-economic inequality (10.0 p.p., 128.4\%), and referent sexual orientation inequality (4.9 p.p., 59.8\%). Total and individual contributions exceeding $100 \%$ are partly a reflection of the contributions representing point estimates rather than fixed parameters.
Moreover, in the presence of counteracting factors, i.e. factors that contributes in the reverse direction (as exemplified by race/ethnicity) and, thus, estimates an inequality that is greater than the one observed in crude analyses, the individual contributions towards the inequality can greatly exceed $100 \%$ of the observed total and explained inequality (as exemplified by material conditions for the joint and referent socio-economic inequality).

The high contribution of material conditions to the joint inequality and referent socio-economic reflects the that the gaps in material conditions between the different groups (low-educated LGBQ adults vs. higheducated heterosexual adults and low-educated heterosexual adults vs. high-educated heterosexual adults) are considerable (as seen in Table 1), in combination with several material conditions being strongly related to smoking itself (as reported in Table 2).

This considerable contribution of material conditions to the joint and referent socio-economic inequalities was possible due to a considerable offsetting contribution of certain factors, particularly race/ethnicity, to the joint ($71.9 \%)$ and referent socio-economic $(-58.9 \%)$ inequalities. Such seemingly paradoxical contributions were explained by the combination of a high percentage of Hispanic adults among low-educated LGBQ (64.3\%; Table 1) and heterosexual (36.6\%) adults on the one hand, and a strong negative association between being Hispanic and current cigarette smoking $(\mathrm{OR}=0.44-0.45$; Table 2$)$ on the other. The offsetting contribution of race/ethnicity and employment status was much less marked for the sexual orientation referent inequality, since the frequency of Hispanics 
Table 3 Summary of Blinder-Oaxaca decomposition analyses of joint inequality, referent socioeconomic inequality, and referent sexual orientation inequality in current cigarette smoking

\begin{tabular}{|c|c|c|c|c|c|c|c|c|c|}
\hline & \multicolumn{3}{|c|}{$\begin{array}{l}\text { Joint inequality: low-educated } \\
\text { LGBQ adults (group1) vs. } \\
\text { high -educated heterosexual } \\
\text { adults (group2) }\end{array}$} & \multicolumn{3}{|c|}{$\begin{array}{l}\text { Referent socio-economic } \\
\text { inequality: low-educated } \\
\text { heterosexual adults (group1) } \\
\text { vs. high-educated } \\
\text { heterosexual adults (group2) }\end{array}$} & \multicolumn{3}{|c|}{$\begin{array}{l}\text { Referent sexual orientation } \\
\text { inequality: high-educated } \\
\text { LGBQ adults (group1) vs. } \\
\text { high-educated heterosexual } \\
\text { adults (group2) }\end{array}$} \\
\hline & Absolute & Relative & $P$ value & Absolute & Relative & $P$ value & Absolute & Relative & $P$ value \\
\hline Group1 & 24.21 & & $<0.001$ & 29.85 & & $<0.001$ & 27.53 & & $<0.001$ \\
\hline Group2 & 17.30 & & $<0.001$ & 17.30 & & $<0.001$ & 17.30 & & $<0.001$ \\
\hline Difference & 6.90 & & 0.015 & 12.55 & & $<0.001$ & 10.23 & & $<0.001$ \\
\hline Explained & 7.00 & 101.4 & $<0.001$ & 7.80 & 62.1 & $<0.001$ & 8.21 & 80.2 & $<0.001$ \\
\hline unexplained & -0.10 & -1.4 & 0.946 & 4.75 & 37.9 & $<0.001$ & 2.02 & 19.8 & 0.025 \\
\hline \multicolumn{10}{|l|}{ Contributions } \\
\hline Socio-demographic factors & -3.90 & -55.7 & & -4.08 & -52.3 & & 0.93 & 11.3 & \\
\hline Gender & -0.45 & -6.4 & 0.08 & 0.31 & 4.0 & 0.007 & -0.53 & -6.4 & 0.001 \\
\hline Age & 0.77 & 11.1 & 0.02 & -0.74 & -9.5 & $<0.001$ & 0.59 & 7.2 & 0.022 \\
\hline Race/ethnicity & -5.03 & -71.9 & $<0.001$ & -4.59 & -58.9 & $<0.001$ & -0.80 & -9.7 & 0.001 \\
\hline Marital status & 0.81 & 11.6 & 0.008 & 0.94 & 12.0 & $<0.001$ & 1.66 & 20.3 & $<0.001$ \\
\hline Material conditions & 9.86 & 140.9 & & 10.01 & 128.4 & & 4.91 & 59.8 & \\
\hline Annual household income & 4.36 & 62.3 & $<0.001$ & 5.03 & 64.6 & $<0.001$ & 1.75 & 21.3 & $<0.001$ \\
\hline Employment status & -0.75 & -10.8 & 0.003 & -1.04 & -13.4 & $<0.001$ & -0.16 & -2.0 & 0.168 \\
\hline Receiving assistance & 0.56 & 7.9 & 0.012 & 0.78 & 10.0 & $<0.001$ & 0.28 & 3.5 & 0.004 \\
\hline Housing & 2.28 & 32.6 & $<0.001$ & 1.77 & 22.7 & $<0.001$ & 1.85 & 22.5 & $<0.001$ \\
\hline Health insurance & 3.42 & 48.8 & $<0.001$ & 3.47 & 44.4 & $<0.001$ & 1.19 & 14.5 & $<0.001$ \\
\hline Marketing-related variables & -1.09 & -15.5 & & -0.37 & -4.7 & & 1.15 & 14.0 & \\
\hline Exposure to contextual-level targeting advertisement & 0.00 & -0.1 & 0.89 & 0.00 & 0.0 & 0.906 & -0.01 & -0.1 & 0.79 \\
\hline Exposure to targeted tobacco marketing & -0.64 & -9.2 & 0.016 & -0.29 & -3.7 & 0.189 & 0.93 & 11.3 & 0.004 \\
\hline Exposure to media advertisement & -0.44 & -6.2 & 0.094 & -0.08 & -1.0 & 0.501 & 0.23 & 2.8 & 0.076 \\
\hline Psychosocial factors & 2.12 & 30.3 & & 2.23 & 28.6 & & 1.68 & 20.5 & \\
\hline Perceived quality of life & 1.73 & 24.8 & 0.001 & 1.75 & 22.4 & $<0.001$ & 0.98 & 11.9 & $<0.001$ \\
\hline Satisfaction with social relations & 0.39 & 5.5 & 0.082 & 0.48 & 6.2 & $<0.001$ & 0.71 & 8.6 & $<0.001$ \\
\hline
\end{tabular}

Bold numbers indicate absolute and relative contributions per group of variables (subtotal)

was more similar in high-educated LGBQ (19.1\%) and high-educated heterosexual (12.0\%) adults.

Among material conditions, annual household income (62.3\%), health insurance (48.8\%) and housing (32.6\%) made the largest contributions to the joint inequality. These contributions were mainly attributed to the $4-5$ times higher proportions of low annual household income $(49.5 \%$, Table 1$)$ and absence of health insurance (42.8\%) among low-educated LGBQ adults, as compared to high-educated heterosexual adults (9.43 and 10.46\% respectively). Similarly, the proportion of adults with rented housing among low-educated LGBQ was double $(65.3 \%)$ that of high-educated heterosexual adults (31.3\%). The same material conditions were the most important for the referent socio-economic and sexual orientation inequalities, although their contribution were not as dominant for the referent sexual orientation inequalities mostly due to smaller income inequalities between high-educated heterosexual and LGBQ groups (Table 1).

Psychosocial factors made the second largest contributions to the joint inequality (2.1 p.p., 30.3\%), referent socio-economic inequality (2.2 p.p., $28.9 \%)$, and referent sexual orientation inequality (1.68 p.p., 20.5\%). These contributions came from mainly perceived quality of life, attributed to quality of life being a strong predictor of smoking (Table 2), in combination with fair and poor quality of life being 3-4 times more frequent among low-educated LGBQ (24.4 and 2.2\%) and heterosexual adults (18.3 and 2.2\%) as compared to high-educated heterosexual adults (6.3 and 0.7\%). A similar but less pronounced pattern for quality of life was seen for the referent sexual orientation inequality $(11.9 \%$ contribution), but for which satisfaction with social relations also contributed moderately (8.6\%). This contribution was 


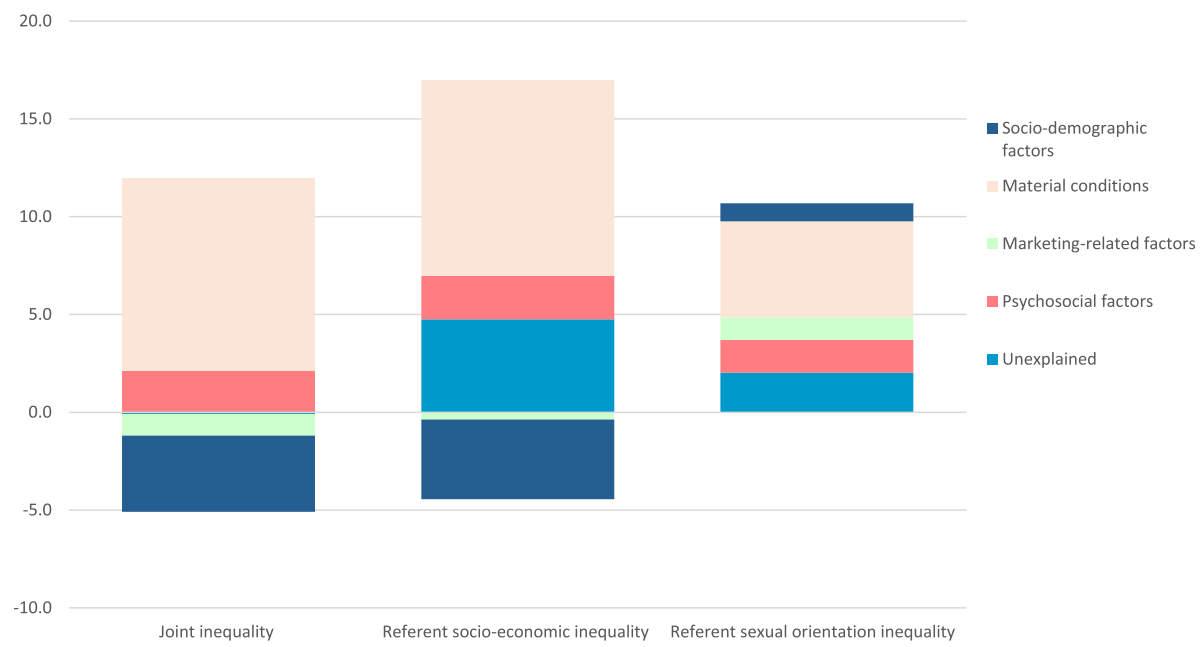

Fig. 1 Absolute contributions of explanatory factors to the joint inequality, referent socio-economic inequality, and referent sexual orientation inequality

explained by a higher proportion of not at all satisfied with social relations among high-educated LGBQ (4.4\%) as compared to high-educated heterosexual adults (2.0\%).

Tobacco marketing-related variables made positive contribution to only referent sexual orientation inequality. This contribution came mainly from exposure to targeted tobacco marketing (11.3\%) that made moderately large contributions to this inequality, attributed to exposure to targeted tobacco marketing being considerably more frequent among the high-educated LGBQ than among high-educated heterosexual groups.

In addition to the offsetting contribution of race/ethnicity commented on above, certain of the remaining socio-demographic factors also contributed towards or against the inequality in smoking. Marital status made an important contribution specifically to sexual orientation referent inequality (20.3\%), as never being married was more frequent among high-educated LGBQ adults than among high-educated heterosexual groups. Last, gender had offsetting contributions to the joint inequality $(-6.4 \%, p>0.08)$ and referent sexual orientation inequality $(-6.4 \%, p<0.01)$, and a small significant but significant positive contribution to the referent socioeconomic inequalities $(4 \%, p<0.05)$. In contrast, age made positive contributions to the joint inequality $(11.1 \%, \mathrm{p}<0.05)$ and the referent sexual orientation inequality $(7.2 \%, \mathrm{p}<0.05)$, but a small significant negative contribution to the referent socio-economic inequality $(-9.7 \%, \mathrm{p}<0.05)$.

\section{Discussion}

The present study examined to what degree intersectional inequalities in smoking by education and sexual orientation could be attributed to inequalities in indicators of multiple social processes. Inequalities in smoking at the intersection of education and sexual orientation are primarily explained by inequalities in material conditions, with a moderate importance of psychosocial factors. More specifically, the joint and the referent socio-economic inequalities were largely attributed to material conditions (annual household income, housing, and health insurance) and to a smaller degree to perceived quality of life. However, annual household income was the main contributor to these inequalities. The referent sexual orientation inequality was additionally explained by marital status (i.e. being single) and exposure to individual-targeting tobacco advertising. These findings are of a significant importance for research, policy, and practice aiming for equity in tobacco control, and by extension also for equity in morbidity and mortality in tobacco-related diseases.

Our study showed that material disadvantage, namely financial disadvantage, is the most universally important social process reinforcing inequalities in cigarette smoking at the intersection of education and sexual orientation. This finding is in accordance with previous studies highlighting the important role of material disadvantage in explaining health inequalities [48, 49]. Moreover, this study expands current knowledge by suggesting that material inequity is not a pathway of relevance merely to socioeconomic inequalities, but is of broader relevance for inequalities in smoking across the entire intersectional space of SES and sexual orientation, including between high-educated heterosexual and LGBQ adults. This points for the need to address financial disadvantage as a way to tackle social inequalities in cigarette smoking more broadly.

The ubiquitous contribution of material disadvantage to intersectional inequalities reflects unequal access to 
material resources between the doubly advantaged group (high-educated heterosexual adults) as compared to other doubly and singly disadvantaged groups, which may be translated into adoption of risky health behaviors among the disadvantaged groups. This finding suggests that contrary to heterosexual adults, for whom education might confer a certain level of material advantage, LGBQ adults in the U.S. are still facing multiple barriers constraining their access to material resources regardless of their educational level. For example, despite the progress towards adopting policies prohibiting discrimination based on sexual orientation in 33 states in the U.S. [50], sexual orientation discrimination in the workplace is still pervasive and widespread [51], which might limit, among others, LGBQ adults' access to promotions and work benefits. A comparable relative material disadvantage among LGBQ people, possibly rooted in structural barriers on the labor market and in working life and expressed in health inequalities, have also been noted in northern European contexts [52].

As a contrast to the universal importance of material conditions, one of the interesting findings of our study is the complex role individual-targeted tobacco advertising played in the studied intersectional space. Although strongly related to smoking, it was exclusively important for the referent sexual orientation inequality in smoking, but not for the joint or referent socio-economic inequalities in smoking; which illustrates how one exposure very strongly related to smoking by itself potentially but not necessarily is relevant for the corresponding social inequalities in smoking. Its contribution was rooted in particularly frequent exposure reported by high-educated LGBQ people as compared to the other groups, including low-educated LGBQ people. This may be explained by the different marketing strategies adopted by tobacco companies when targeting different. For example, strategies targeting low SES people $[27,28]$ may include distributing discount offers at point-of-sale [27], which was not captured by the this study. In contrast, tobacco marketing strategies targeting the LGBQ community may look different $[29,30,53]$; for example, sponsoring LGBQ events and targeting gay bars. Some tobacco brand marketing campaigns have connected tobacco use to LGBQ issues, such as linking freedom to smoke with freedom to marry [29]. More specifically, the higher exposure to individualtargeted tobacco advertising among high-educated LGBQ, instead of LGBQ people more generally, could be associated with stronger participation in the LGBQ community among high SES LGBQ adults [54]. Indeed, affinity [55] and participation in the LGBQ community [56, 57] have been associated with smoking and substance use among LGBQ people. It is also possible that messages that appeal more to well-educated LGBQ people is part of strategic effort by tobacco companies.
Taken together, this specific finding may reflect how different intersectional groups, through specific oppressive social processes, are specifically targeted and exploited for profit, which in turn sheds light on how unexpected and complex population patterns of health-damaging behaviors arise. It, thereby, illustrates the unique knowledge gained from an intersectional approach taking into account both social positions and their expressions in social processes [21].

A further finding warranting a comment is the strong offsetting contribution of race/ethnicity. As we have noted in our previous report, low-educated LGBQ reported less smoking than expected. The decomposition analyses of the present study shows that a large part of this low prevalence of smoking is explained by the high frequency of Hispanic adults, which smoke to a lesser degree than non-Hispanic White adults as also indicated by the national patterns in cigarette smoking among different racial/ethnic groups [5]. Expressed differently, if all ethnic groups smoked equally, the joint inequality would have been considerably larger; 11.9.p.p instead of 6.9 p.p.; and a similarly-sized increase would have been estimated for the SES referent inequality. This suggests that the impact of double socioeconomic and sexual orientation-related disadvantage on smoking might be partially hidden by the outcome-specific protective presence of ethnic groups that nonetheless indeed are socially disadvantaged. This observation illustrates the complexity that comes from an intersectional approach to inequalities in smoking, and is one specific issue that requires further study.

\section{Study limitations}

Our study has several limitations. Despite the importance of psychosocial factors such as perceived discrimination [52] and victimization [14] in explaining socioeconomic inequalities and sexual orientation inequalities in cigarette smoking, these factors were not included in the models. This is mainly due to the absence of variables that might capture these factors in the data set. Similarly, macro-level factors that might explain inequalities in cigarette smoking such as living in areas with smoking-free polices were not included in the models [58]. Decomposition analysis is considered an illustrative method that allows identifying factors contributing to health inequalities. However, this method does not suggest causal inference, which is a particular limitation when using a cross-sectional design, as the present study.

\section{Conclusions}

This study shows that material disadvantage plays a dominant role in explaining inequalities in cigarette smoking affecting not only the doubly disadvantaged group of loweducated LGBQ but also other socioeconomic and sexual orientation groups of single disadvantage. This finding 
suggests that reducing smoking inequalities in cigarette smoking among U.S. adults more broadly requires addressing the underlying inequalities in material disadvantage among marginalized groups.

\section{Abbreviation}

LBGQ: Lesbian, bisexual, gay, and queer/questioning; OR: Odds ratio; p.p.: percentage point; PATH: Population Assessment of Tobacco and Health; SES: Socio-economic status

\section{Acknowledgements}

None.

\section{Authors' contributions}

NA, PEG, and JLP conceived the study. NA conducted the data analysis and interpreted the data with guidance from PEG. NA drafted the manuscript under the supervision of PEG and JLP, and both PEG and JLP revised the manuscript for intellectual content. All authors read and approved the final draft.

\section{Funding}

This research did not receive any specific grant from funding agencies in the public, commercial, or not-for-profit sectors.

\section{Availability of data and materials}

The dataset analyzed in this study is available from: https://www.icpsr.umich. edu/icpsrweb/NAHDAP/studies/36498/datadocumentation.

\section{Ethics approval and consent to participate}

Not applicable.

\section{Consent for publication}

Not applicable.

\section{Competing interests}

The authors declare that they have no competing interests.

\section{Author details}

'Division of Social and Behavioral Health, University of Nevada, Reno, USA. ${ }^{2}$ Division of Social and Behavioral Health/Health Administration and Policy, University of Nevada, Reno, USA. ${ }^{3}$ Department of Health, Behavior, and Society, Johns Hopkins Bloomberg School of Public Health, Baltimore, MD, USA. ${ }^{4}$ Department of Public Health and Clinical Medicine, Umeå University, Umeå, Sweden.

Received: 22 April 2019 Accepted: 7 July 2019

Published online: 17 July 2019

\section{References}

1. Drope J, Liber AC, Cahn Z, Stoklosa M, Kennedy R, Douglas CE, Henson R, Drope J. Who's still smoking? Disparities in adult cigarette smoking prevalence in the United States. CA Cancer J Clin. 2018;68(2):106-15.

2. U.S. Department of Health and Human Services. The Health Consequences of Smoking 50 Years of Progress: A Report of the Surgeon General. Atlanta: U.S. Department of Health and Human Services, Centers for Disease Control and Prevention, National Center for Chronic Disease Prevention and Health Promotion, Office on Smoking and Health. 2014. Available from: https:// www.cdc.gov/tobacco/data_statistics/sgr/50th-anniversary/index.htm. Accessed 10 Dec 2018.

3. Substance Abuse and Mental Health Services Administration. Results from the 2016 National Survey on Drug Use and Health: Detailed Tables. Rockville: Substance Abuse and Mental Health Services Administration, Center for Behavioral Health Statistics and Quality; 2014. Available from: https://www.samhsa.gov/data/sites/default/files/NSDUH-DetTabs-2016/ NSDUH-DetTabs-2016.pdf. Accessed 15 Dec 2018.

4. Pampel F, Legleye S, Goffette C, Piontek D, Kraus L, Khlat M. Cohort changes in educational disparities in smoking: France, Germany and the United States. Soc Sci Med. 2015;127:41-50.
5. Wang TW, Asman K, Gentzke AS, Cullen KA, Holder-Hayes E, Reyes-Guzman C, Jamal A, Neff L, King BA. Tobacco product use among adults_-United States, 2017. Morb Mortal Wkly Rep. 2018;67(44):1225.

6. McCabe SE, Matthews AK, Lee JG, Veliz P, Hughes TL, Boyd CJ. Tobacco use and sexual orientation in a National Cross-sectional Study: age, race/ ethnicity, and sexual identity-attraction differences. Am J Prev Med. 2018; 54(6):736-45.

7. Wheldon CW, Kaufman AR, Kasza KA, Moser RP. Tobacco use among adults by sexual orientation: findings from the population assessment of tobacco and health study. LGBT health. 2018;5(1):33-44.

8. Rosario M, Li F, Wypij D, Roberts AL, Corliss HL, Charlton BM, Frazier AL, Austin SB. Disparities by sexual orientation in frequent engagement in cancer-related risk behaviors: a 12-year follow-up. Am J Public Health. 2016; 106(4):698-706.

9. Singh GK, Williams SD, Siahpush M, Mulhollen A. Socioeconomic, ruralurban, and racial inequalities in US cancer mortality: part I-all cancers and lung cancer and part II-colorectal, prostate, breast, and cervical cancers. J Cancer Epidemiol. 2011;2011:107497.

10. Matthews AK, Hotton A, DuBois S, Fingerhut D, Kuhns LM. Demographic, psychosocial, and contextual correlates of tobacco use in sexual minority women. Res Nurs Health. 2011;34(2):141-52.

11. Pelster AD, Fisher CM, Irwin JA, Coleman JD, McCarthy MA. Tobacco use and its relationship to social determinants of health in LGBT populations of a Midwestern state. LGBT Health. 2015;2(1):71-6.

12. Jannat-Khah DP, Dill LJ, Reynolds SA, Joseph MA. Stress, socializing, and other motivations for smoking among the lesbian, gay, bisexual, transgender, and queer community in new York City. Am J Health Promot. 2018:32(5):1178-86.

13. Hughes TL, Johnson TP, Matthews AK. Sexual orientation and smoking: results from a multisite women's health study. Subst Use Misuse. 2008;43(89):1218-39.

14. Blosnich J, Lee JG, Horn K. A systematic review of the aetiology of tobacco disparities for sexual minorities. Tob Control. 2013;22(2):66-73.

15. Balsam KF, Beadnell B, Riggs KR. Understanding sexual orientation health disparities in smoking: a population-based analysis. Am J Orthopsychiatry. 2012:82(4):482.

16. Kim JE, Tsoh JY. Cigarette Smoking Among Socioeconomically Disadvantaged Young Adults in Association With Food Insecurity and Other Factors. Prev Chron Dis. 2016;13:E08.

17. Martinez SA, Beebe LA, Thompson DM, Wagener TL, Terrell DR, Campbell JE. A structural equation modeling approach to understanding pathways that connect socioeconomic status and smoking. PLoS One. 2018;13(2):e0192451.

18. Richman LS, Zucker A. Quantifying intersectionality: an important advancement for health inequality research. Soc Sci Med. 2019;226:246-8.

19. Jackson JW, VanderWeele TJ. Intersectional decomposition analysis with differential exposure, effects, and construct. Soc Sci Med. 2019;226:254-9.

20. Evans CR. Adding interactions to models of intersectional health inequalities: comparing multilevel and conventional methods. Soc Sci Med. 2019:221:95-105.

21. Bauer GR. Incorporating intersectionality theory into population health research methodology: Challenges and the potential to advance health equity. Soc Sci Med. 2014;110:10-7.

22. Corliss HL, Rosario M, Birkett MA, Newcomb ME, Buchting FO, Matthews AK. Sexual orientation disparities in adolescent cigarette smoking: intersections with race/ethnicity, gender, and age. Am J Public Health. 2014;104(6):1137-47.

23. Hsieh N, Ruther M. Sexual minority health and health risk factors: intersection effects of gender, race, and sexual identity. Am J Prev Med. 2016;50(6):746-55

24. Wheldon CW, Watson RJ, Fish JN, Gamarel K. Cigarette Smoking Among Youth at the Intersection of Sexual Orientation and Gender Identity. LGBT health. 2019;6(5):235-41.

25. Casetta B, Videla AJ, Bardach A, Morello P, Soto N, Lee K, Camacho PA, Hermoza Moquillaza RV, Ciapponi A. Association between cigarette smoking prevalence and income level: a systematic review and meta-analysis. Nicotine Tob Res. 2016;19(12):1401-7.

26. Widome R, Joseph AM, Hammett P, Van Ryn M, Nelson DB, Nyman JA, Fu SS. Associations between smoking behaviors and financial stress among low-income smokers. Prev Med Rep. 2015:2:911-5.

27. Brown-Johnson CG, England LJ, Glantz SA, Ling PM. Tobacco industry marketing to low socioeconomic status women in the USA. Tobacco control. 2014;23(e2):e139-46. 
28. Lee JG, Henriksen L, Rose SW, Moreland-Russell S, Ribisl KM. A systematic review of neighborhood disparities in point-of-sale tobacco marketing. Am J Public Health. 2015;105(9):e8-18.

29. Emory K, Buchting FO, Trinidad DR, Vera L, Emery SL. Lesbian, gay, bisexual, and transgender (LGBT) view it differently than non-LGBT: exposure to tobacco-related couponing, e-cigarette advertisements, and anti-tobacco messages on social and traditional media. Nicotine Tob Res. 2018;21(4):513-22

30. Dilley JA, Spigner C, Boysun MJ, Dent CW, Pizacani BA. Does tobacco industry marketing excessively impact lesbian, gay and bisexual communities? Tob Control. 2008;17(6):385-90.

31. Gustafsson PE, Sebastian MS, Mosquera PA. Meddling with middle modalities: a decomposition approach to mental health inequalities between intersectional gender and economic middle groups in northern Sweden. Glob Health Action. 2016:9(1):32819.

32. Sinning M, Hahn M, Bauer TK. The blinder-Oaxaca decomposition for nonlinear regression models. Stata J. 2008;8(4):480-92.

33. Hyland A, Ambrose BK, Conway KP, Borek N, Lambert E, Carusi C, Taylor K, Crosse S, Fong GT, Cummings KM, Abrams D. Design and methods of the population assessment of tobacco and health (PATH) study. Tob Control. 2017:26(4):371-8.

34. United States Department of Health and Human Services. National Institutes of Health. National Institute on Drug Abuse, and United States Department of Health and Human Services. Food and Drug Administration. Center for Tobacco Products. Population Assessment of Tobacco and Health (PATH) Study [United States] Public-Use Files, User Guide. ICPSR36498-v6. Ann Arbor: Inter-university Consortium for Political and Social Research [distributor]; 2017. https://doi.org/10.3886/ICPSR36498.userguide34.

35. Jackson JW, Williams DR, VanderWeele TJ. Disparities at the intersection of marginalized groups. Soc Psychiatry Psychiatr Epidemiol. 2016;51(10):1349-59.

36. United States Department of Health andHuman Services. National Institutes ofHealth. National Institute on Drug Abuse, United States Department of Health andHuman Services. Food and DrugAdministration. Center for TobaccoProducts. Population Assessment of Tobaccoand Health (PATH) Study [UnitedStates] Public-Use Files. Codebook for Wave 2: Adult Data. Population Assessment of Tobaccoand Health (PATH) Study [UnitedStates] Public-Use Files. Codebook for Wave 2: Adult Data.

37. Emory K, Kim Y, Buchting F, Vera L, Huang J, Emery SL. Intragroup variance in lesbian, gay, and bisexual tobacco use behaviors: evidence that subgroups matter, notably bisexual women. Nicotine Tob Res. 2015;18(6): 1494-501.

38. Alves J, Kunst AE, Perelman J. Evolution of socioeconomic inequalities in smoking: results from the Portuguese national health interview surveys. BMC Public Health. 2015;15(1):311.

39. Siegel M. Measuring age-specific variations in income-related inequalities in smoking behavior in Germany. Health Psychol Behav Med. 2014;2(1):412-23.

40. Ortiz KS, Duncan DT, Blosnich JR, Salloum RG, Battle J. Smoking among sexual minorities: are there racial differences? Nicotine Tob Res. 2015;17(11):1362-8.

41. Ramsey MW Jr, Chen-Sankey JC, Reese-Smith J, Choi K. Association between marital status and cigarette smoking: variation by race and ethnicity. Prev Med. 2019;119:48-51.

42. Lindström M. Social capital, economic conditions, marital status and daily smoking: a population-based study. Public Health. 2010;124(2):71-7.

43. Midi H, Sarkar SK, Rana S. Collinearity diagnostics of binary logistic regression model. J Interdisciplinary Mathematics. 2010;13(3):253-67.

44. Jann B. The blinder-Oaxaca decomposition for linear regression models. Stata J. 2008;8(4):453-79.

45. O'Donnell O, Van Doorslaer E, Wagstaff A, Lindelow M. Analyzing health equity using household survey data: a guide to techniques and their implementation. Chapter 12: Explaining differences between groups: Oaxaca decomposition. Washington, DC: The World Bank; 2007. p. 147-57. Available from: http://web.worldbank.org/archive/website01411/WEB/ IMAGES/HEALTHEQ.PDF.

46. Oaxaca R. Male-female wage differentials in urban labor markets. Int Econ Rev. 1973;1:693-709.

47. Yun MS. Decomposing differences in the first moment. Econ Lett. 2004 82(2):275-80.

48. Moor I, Spallek J, Richter M. Explaining socioeconomic inequalities in selfrated health: a systematic review of the relative contribution of material, psychosocial and behavioural factors. J Epidemiol Community Health. 2017; 71(6):565-75.
49. Skalická V, Van Lenthe F, Bambra C, Krokstad S, Mackenbach J. Material, psychosocial, behavioural and biomedical factors in the explanation of relative socio-economic inequalities in mortality: evidence from the HUNT study. Int J Epidemiol. 2009;38(5):1272-84

50. Human Rights Campaign. State Maps of Laws \& Policies-Employment. Human Rights Campaign. Human Rights Campaign; 2018. Available from: https://www.hrc.org/state-maps/employment. [cited 2019Jan7]

51. Brown A. As Congress considers action again, $21 \%$ of LGBT adults say they faced workplace discrimination. Pew Research Center. Pew Research Center; 2014. Available from: http://www.pewresearch.org/fact-tank/2013/11/04/ascongress-considers-action-again-21-of-lgbt-adults-say-they-faced-workplacediscrimination/. [cited 2019Jan8]

52. Gustafsson PE, Linander I, Mosquera PA. Embodying pervasive discrimination: a decomposition of sexual orientation inequalities in health in a population-based cross-sectional study in northern Sweden. Int J Equity Health. 2017;16(1):22.

53. Fallin A, Davis B. LGBT organisation successfully advocated for ban on tobacco promotions in San Jose, California. Tobacco Control. 2016;25(5): 504-5.

54. Mallon GP. Oh, Canada: the experience of working-class gay men in Toronto. J Gay Lesbian Soc Serv. 2001;12(3-4):103-17.

55. D'Avanzo PA, Halkitis PN, Yu K, Kapadia F. Demographic, mental health, behavioral, and psychosocial factors associated with cigarette smoking status among young men who have sex with men: the P18 cohort study. LGBT Health. 2016;3(5):379-8.

56. Demant $D$, Hides L. WhiteKM, Kavanagh DJ. Effects of participation in and connectedness to the LGBT community on substance use involvement of sexual minority young people. Addict Behav. 2018;81:167-74.

57. Barnhill M, Lee J, Rafferty A. Health inequities among lesbian, gay, and bisexual adults in North Carolina, 2011-2014. Int J Environ Res Public Health. 2017;14(8):835.

58. Wintemberg J, McElroy JA, Ge B, Everett KD. Can Smoke-Free Policies Reduce Tobacco Use Disparities of Sexual and Gender Minorities in Missouri? Nicotine Tob Res. 2017;19(11):1308-14.

\section{Publisher's Note}

Springer Nature remains neutral with regard to jurisdictional claims in published maps and institutional affiliations.
Ready to submit your research? Choose BMC and benefit from:

- fast, convenient online submission

- thorough peer review by experienced researchers in your field

- rapid publication on acceptance

- support for research data, including large and complex data types

- gold Open Access which fosters wider collaboration and increased citations

- maximum visibility for your research: over $100 \mathrm{M}$ website views per year

At $\mathrm{BMC}$, research is always in progress.

Learn more biomedcentral.com/submissions 